\title{
Nobody Does it Better: A Patient Physician Perspective of Asthma Management
}

\author{
Noelle Morgan · Ian Clifton
}

Received: February 20, 2019 / Published online: March 6, 2019

(C) The Author(s) 2019

\begin{abstract}
This article, co-authored by a patient living with asthma and a consultant physician in respiratory medicine, describes the patient's experience of asthma. The physician then discusses asthma management in the context of the patient's experiences.
\end{abstract}

Keywords: Asthma; Patient perspective; Respiratory

\section{PATIENT'S EXPERIENCE}

As I approach the milestone of my 50th birthday, I reflect on the many challenges that life has thrown at me. Having a chronic, long-term condition, however, isn't one of them. Asthma means different things to different people; for me, it is a part of me, it is who I am and therefore I have grown to embrace it.

Enhanced digital features To view enhanced digital features for this article go to https://doi.org/10.6084/ m9.figshare.7745306.

N. Morgan

Oxfordshire, UK

I. Clifton ( $\square)$

Department of Respiratory Medicine, St James's

University Hospital, Leeds, UK

e-mail: i.clifton@nhs.net
A surprising statement for some perhaps, considering the UK has the highest asthma death rate in the world and approximately 5.4 million people in the UK live with the disease-that is one in every 11 people. It's a complex condition and not one to be taken lightly but I won't let it beat me nor dampen my spirits. I have had asthma since I was a small child and I have had numerous chest infections, countless antibiotics, tons of steroids and so many inhalers that I am surprised I don't rattle; well occasionally I do. But it could be worse.

I am not sure where this courage, resilience and stubbornness came from. Perhaps from my mother, a paediatrician who ran her own asthma clinic, whose passion and determination I witnessed to give these poorly children the best life possible. Or perhaps it was from the respiratory consultant who told me categorically at the age of 13 that I would never be able to run a marathon. I then had my first goal!

Having asthma has not been an easy journey and it can be so scary. I tell people that having a tight chest or an asthma attack is like trying to breathe through a straw or trying to breathe up hill and never reaching the top. My list of asthma triggers is as long as your arm (house dust, cats, dogs, horses, feathers, orange juice, white wine, humidity, pollen, cold, stress etc.) and I feel I need to be on high alert and super vigilant whenever I go out to keep myself safe. I have grown to understand that despite all those 
around me the only person who can take care of me is me.

At the age of 44 , things took a real downward spiral in my health and my super active, happygo-lucky life as I knew it came to a standstill. I had a 4-year episode, on and off of a nasty Pseudomonas infection and was eventually diagnosed with bronchiectasis. My pulmonologist gave me course after course of antibiotics and upped my inhaler until I was on the highest dose of Seretide 500 BD. When the cough kept coming back she then added additional inhaled steroids, Qvar. Frankly I sounded like I smoked 40 a day. I could barely run 200 yards without stopping with chest pains and my persistent hacking cough was embarrassing so much so that people would turn around and stare. I honestly thought I was going to spend the rest of my years on oxygen or even die. Alarms bells began to ring even when calling the pharmacist for a repeat prescription or seeing another doctor for something else and they would comment on how high a dose I was on. I decided enough was enough; none of this was making sense and I wasn't getting answers or getting better. I went and saw a consultant at the Nuffield and for the first time, someone was looking at me as a whole person and not just treating the symptom. He suggested a totally different approach, felt less steroids would be better for me and started to slowly wean me off the high dosage of steroids. After a 3-month course of low dose antibiotic, I have been cough-free for 2 years and on the lowest dose of inhaled steroids ever (100 BD) and with a peak flow of 610 .

Self-management is key; I have learnt about my condition through reading and research and asking questions. I have learnt to push back at the doctors if I don't feel that their advice is right for me and learnt to converse with my GP from an adult-adult perspective; it needs to be a partnership; a coaching conversation. The GP cannot be a master of all trades and doesn't have all the answers. I have said no to a cheaper generic inhaler which may save the practice money but might set back my condition-an approach made very clear in the NICE guidelines. Additionally, I know now which antibiotics may be good for chest infections but can cause side effects on other aspects of my life and so have asked for alternatives (fluoroquinolones and tendinitis-not good for running).

I have made exercise a massive part of my life. I go to the gym five times a week and run when I can. I don't think it is a coincidence that I am a runner and my asthma is so well controlled these days. I wish other asthmatics could see the benefit of some form of weekly cardio exercise on lung function, even if it is just starting with baby steps. After being told at the age of 13 that my dream of running the London Marathon would never be fulfilled, I have since gone on to run four marathons-London included, where I ran for Asthma UK. Trust me, there will be others. When I run I feel alive, invincible and like I don't have asthma; I feel the air in my lungs and I can breathe. Running helps with my mental health too; stress, as we know, plays a big part in exacerbating asthma attacks, so keeping a positive mindset is imperative to keeping me well.

I do believe there is an unmet need in the community in that Asthma UK does not offer any local face-to-face support groups for patients and their carers to help them cope with the psychological and emotional aspects of the disease.

As the Carly Simon song goes, "Nobody does it better"; we all need to take responsibility for managing our health.

\section{PHYSICIAN'S RESPONSE}

Noelle's article is very illuminating as it gives some very interesting and pertinent insights into the challenges of care for people with asthma.

Asthma is defined as a chronic inflammatory condition of the airways. The airway inflammation is associated with hyperresponsiveness of the airways and variable airflow obstruction [1]. Asthma is a common condition and was first described by Hippocrates approximately 2500 years ago. Worldwide we estimate that 300 million people are affected, but prevalence of the condition varies widely in different populations, and it appears to lie in the range of $1-18 \%$ [2]. As Noelle highlights, within the UK it is estimated that 5.4 million people currently 
receive asthma treatment [2]. During childhood asthma tends to be commoner in boys; however, during adulthood the condition tends to be more frequent in women.

As a clinician when making a diagnosis of asthma, the history from the patient is of crucial importance. When assessing a patient with asthma, we need to identify the presence of the key symptoms of intermittent and variable breathlessness, wheeze and cough. These symptoms are usually worsened on exposure to trigger factors that the patient can usually identify. In Noelle's article she mentions several triggers that are of relevance to her symptoms. Once we have established the clinical history, we then undertake diagnostic tests to help confirm the diagnosis of asthma. The tests we use broadly speaking look to confirm the presence of variable airways obstruction, bronchial hyperreactivity or airways inflammation (Table 1). As a physician with an interest in the care of people with severe asthma, I also recognise the importance of having a whole person approach to those individuals with difficult-to-control asthma symptoms. The need for a detailed assessment of a person with difficult-to-control asthma is well recognised [3] and when undertaken it is not unusual that either an alternative or co-existent pathology is identified. Subsequent appropriate management can then result in an improvement in asthma control, as demonstrated by Noelle. The identification and treatment of her co-existent bronchiectasis resulted in improvement in asthma control and a reduction in intensity of asthma therapy.

Over the years as our understanding of asthma has changed, we now appreciate that asthma is not one disease, but the condition can be subdivided into different forms or phenotypes of asthma [4]. This understanding of the different forms of asthma is critical as we can now start to understand that different people's asthma responds to different asthma therapies and we need to be focused on ensuring our patients get the right therapies, so we can aim for optimal control of symptoms whilst minimizing the risk of side effects.

A stepwise approach to asthma care has long been established in asthma practice [5] and this ensures that asthma treatment is increased or decreased according to the individual patients needs and symptoms. The aim of asthma management is to have control of day-to-day symptoms, normal lung function and have no exacerbations of the disease. Exacerbations of asthma are usually treated with high doses of oral steroids which can have significant side effects including weight gain, osteoporosis, thinning of the skin and fluid retention. As well as trying to control day-to-day symptoms it is also very important to reduce the risk of future exacerbations, aiming to prevent the long-term consequences of oral corticosteroid usage.

As Noelle suggests in her article, the mainstay of asthma therapy is via inhaled drugs. The inhalers contain corticosteroids which have an anti-inflammatory effect and/or bronchodilators which help improve airflow obstruction. We predominantly use an inhaled route for therapy as this allows for direct delivery of the drug to the lung, thereby maximising action on the target organ, and minimising systemic absorption and side effects. There are a wide variety of inhalers available and one of the challenges in asthma care is ensuring the individual can use the inhaler device approximately [6]. There is no one inhaler device that will suit all patients [7]; therefore it is critical to work collaboratively to ensure the inhaler device suits

Table 1 Diagnostic test for asthma

\begin{tabular}{lll}
\hline Airways obstruction & Bronchial hyperreactivity & Airways inflammation \\
\hline Peak expiratory flow & Histamine challenge & Exhaled nitric oxide testing \\
Spirometry & Methacholine challenge & Sputum eosinophil counts \\
Reversibility testing & Mannitol challenge & \\
\hline
\end{tabular}


the patient and that the patient receives appropriate education and training in the use of the device. It has been recognised that poor inhaler technique is associated with reduced asthma control [8]. Generally, these inhaled therapies are well tolerated, but they do have some side effects such as irritation of the oral cavity (inhaled corticosteroids) or tremor (bronchodilators).

If a person's asthma is more difficult to control then we can add oral therapies such as montelukast [9], theophylline [10] or low dose azithromycin [11]. Montelukast is an anti-inflammatory agent, and generally is well tolerated but can cause sleep and mood disturbance. Theophylline predominantly acts via bronchodilation and can cause gastrointestinal side effects such as nausea. Azithromycin is a macrolide antibiotic that also has anti-inflammatory properties, it is generally well tolerated, but can have gastrointestinal side effects and requires liver function and ECG monitoring. The use of azithromycin in this situation would be supported by randomised controlled trial data, but would be outside of the drug licence within the UK.

In the last few years biological therapies have been developed for people with severe asthma. These are monoclonal antibodies that target specific cytokines within the immune system that are felt to be important in modulating asthma control (Table 2). They are only suitable for use in patients with certain phenotypes or subtypes of asthma. These therapies are delivered by an injection and are generally well tolerated but can be associated with side effects such as injection site irritation and a flu-like reaction. One of the major downsides of these therapies is that the currently have to be

Table 2 Current biological therapies for severe asthma

\begin{tabular}{lll}
\hline Biological therapy & Cytokine & Asthma phenotype \\
\hline Omalizumab & IgE & Atopic \\
Mepolizumab & IL5 & Eosinophilic \\
Reslizumab & IL5 & Eosinophilic \\
Benralizumab & IL5 receptor & Eosinophilic \\
\hline
\end{tabular}

administered in a clinic or hospital environment, but new developments currently will allow for home and/or self-administration in the future.

Another therapy that has been recently established in the care of people with severe asthma is bronchial thermoplasty. This therapy involves the application of gentle heat to the airways via a fibre-optic bronchoscopy. This results in reduction in smooth airways muscle and improvement in asthma control. It is unclear whether the mechanism of action for this therapy is through reduction of the ability of smooth muscle to cause bronchoconstriction or via the reduction in potential reservoir of inflammatory cells. The therapy has been established as effective and safe in both the short and longer term [12, 13]. The main downside of this therapy is the need for three bronchoscopies and the short-term risk of exacerbation peri-procedure.

There are several factors that will influence the choice of therapy for a patient with asthma. These will critically include patient preference, but also previous experience of therapies (either clinician or patient), current level of asthma control, frequency of exacerbations of asthma, as well as specific issues such as funding arrangements for high-cost therapies such as biological therapies and bronchial thermoplasty. Involvement of patient with asthma via shared decision-making has been demonstrated to improve concordance with controller medication and reduce the need to reliever medication [14].

In her article Noelle discusses the role of selfmanagement of her asthma. This is a key component of asthma care and has long been established as a principle in the delivery of asthma treatment [5]. Within my practice I use the Asthma UK self-management plan to help people with asthma to understand their disease and therapy, as well as their understanding of asthma. A key part of providing a self-management plan is to discuss it with the individual and tailor it to their needs. The British Thoracic Society guidelines for asthma emphasis that to achieve a successful self-management programme a combination of written personal action asthma plan alongside education. These 
guidelines also highlight that self-management is not a one-off event, but a process that should be undertaken at all asthma consultations to review, reinforce and extend the individual's ability to self-manage their asthma [15].

It is well recognised that difficult-to-control asthma can have significant effects upon quality of life and it is important to recognise that selfhelp groups or psychological therapies can be an important part of a holistic approach to the management of a person with difficult-to-control asthma.

Noelle demonstrates very well that once her asthma symptoms were well controlled, she was able to undertake regular exercise as well as undertaking the significant challenge of running a marathon. This demonstrates the key importance of clinicians and people with asthma working in partnership to ensure accurate diagnosis of asthma, identification of comorbidities and then developing an effective treatment regimen for the individual. It also critically demonstrates the key aims of management of a person's asthma-minimal symptoms, no limitations to activity, normal lung function, and no exacerbations.

Good-quality asthma care relies on a partnership between clinicians and patients; in the words of The Beatles, "We can work it out!"

\section{ACKNOWLEDGEMENTS}

Peer Review. Please note, contrary to the journal's standard single-blind peer-review process, this article was reviewed by a single Editorial Board member.

Funding. No funding or sponsorship was received for this study or publication of this article.

Authorship. All named authors meet the International Committee of Medical Journal Editors (ICMJE) criteria for authorship for this article, take responsibility for the integrity of the work as a whole, and have given their approval for this version to be published.
Disclosures. I. Clifton reports grants from Gilead, grants and personal fees from Novartis, grants and personal fees from AstraZeneca, outside the submitted work. N. Morgan has nothing to disclose.

Compliance with Ethics Guidelines. This article is based on previously conducted studies and does not contain any studies with human participants or animals performed by any of the authors.

Open Access. This article is distributed under the terms of the Creative Commons Attribution-NonCommercial 4.0 International License (http://creativecommons.org/licenses/ by-nc/4.0/), which permits any noncommercial use, distribution, and reproduction in any medium, provided you give appropriate credit to the original author(s) and the source, provide a link to the Creative Commons license, and indicate if changes were made.

\section{REFERENCES}

1. Global Initiative for Asthma. Global strategy for asthma management and prevention. 2012. https:// www.ginasthma.org.

2. Asthma UK. Asthma facts and statistics. https:// www.asthma.org.uk/about/media/facts-andstatistics/. Accessed 30 Nov 2018.

3. Robinson DS, et al. Systematic assessment of difficult-to-treat asthma. Eur Respir J. 2003;22(3): 478-83.

4. Wenzel SE. Asthma phenotypes: the evolution from clinical to molecular approaches. Nat Med. 2012;18(5):716-25.

5. British Thoracic Society. British guideline on the management of asthma. London: British Thoracic Society; 2014.

6. Capstick TG, Clifton IJ. Inhaler technique and training in people with chronic obstructive pulmonary disease and asthma. Expert Rev Respir Med. 2012;6(1):91-101 (quiz 102-3).

7. Lenney J, Innes JA, Crompton GK. Inappropriate inhaler use: assessment of use and patient preference of seven inhalation devices. EDICI. Respir Med. 2000;94(5):496-500. 
8. Melani AS, et al. Inhaler mishandling remains common in real life and is associated with reduced disease control. Respir Med. 2011;105(6):930-8.

9. Joos S, et al. Montelukast as add-on therapy to inhaled corticosteroids in the treatment of mild to moderate asthma: a systematic review. Thorax. 2008;63(5):453-62.

10. Evans DJ, et al. A comparison of low-dose inhaled budesonide plus theophylline and high-dose inhaled budesonide for moderate asthma. N Engl J Med. 1997;337(20):1412-8.

11. Gibson PG, et al. Effect of azithromycin on asthma exacerbations and quality of life in adults with persistent uncontrolled asthma (AMAZES): a randomised, double-blind, placebo-controlled trial. Lancet. 2017;390(10095):659-68.
12. Wechsler ME, et al. Bronchial thermoplasty: longterm safety and effectiveness in patients with severe persistent asthma. J Allergy Clin Immunol. 2013;132(6):1295-302.

13. Cox G, et al. Asthma control during the year after bronchial thermoplasty. $\mathrm{N}$ Engl J Med. 2007;356(13):1327-37.

14. Wilson SR, et al. Shared treatment decision making improves adherence and outcomes in poorly controlled asthma. Am J Respir Crit Care Med. 2010;181(6):566-77.

15. British Thoracic Society. British guideline on the management of asthma. London: British Thoracic Society; 2016. 